\title{
Regulation of the Subcellular Distribution of m4 Muscarinic Acetylcholine Receptors in Striatal Neurons In Vivo by the Cholinergic Environment: Evidence for Regulation of Cell Surface Receptors by Endogenous and Exogenous Stimulation
}

\author{
Véronique Bernard, ${ }^{1}$ Allan I. Levey, ${ }^{2}$ and Bertrand Bloch ${ }^{1}$ \\ ${ }^{1}$ Centre National de la Recherche Scientifique, Unité Mixte de Recherche 5541, Laboratoire d'Histologie-Embryologie, \\ Université Victor Ségalen-Bordeaux 2, 33076 Bordeaux Cedex, France, and ²Emory University Woodruff Memorial \\ Research Building, Atlanta, Georgia 30322
}

Our aim was to determine how the cholinergic environment influences, in vivo, the membrane abundance and the intracellular trafficking of the muscarinic receptor m4 (m4R). Immunohistochemistry at light and electron microscopic level was used to detect the subcellular localization of $\mathrm{m} 4 \mathrm{R}$ in several populations of striatal cholinoceptive neurons, including cholinergic neurons and medium spiny neurons.

(1) In control rats, in cholinergic neurons, m4R is mostly restricted to intracytoplasmic sites involved in its synthesis, especially endoplasmic reticulum. In contrast, m4R is preferentially located at the plasma membrane in cell bodies and dendritic shafts and spines of medium spiny neurons. The density of $\mathrm{m} 4 \mathrm{R}$ was greater at the membrane of perikarya in patches (striatal areas with low acetylcholine activity) than in matrix (striatal areas with high acetylcholine activity). (2) Stimulation of muscarinic receptor with oxotremorine provokes translocation of $\mathrm{m} 4 \mathrm{R}$ from the membrane to endosomes in perikarya and dendrites of medium spiny neurons but has no influence on the localization of m4R in the cytoplasm of cholinergic cell bodies.

Our results suggest that the intraneuronal trafficking and the abundance of membrane-bound $\mathrm{m} 4 \mathrm{R}$ in vivo is under regulation of the cholinergic environment. The m4R subcellular compartmentalization depends on the phenotype of the cholinoceptive neuron and on its neurochemical environment. Such regulation, by modulating availability of receptor for endogenous and exogenous ligands, may play key roles in the response of target neurons.

Key words: endocytosis; G-protein-coupled receptors; patches; matrix; basal ganglia; immunohistochemistry; multivesicular bodies
Classical neurotransmitters, including acetylcholine (ACh), dopamine, or glutamate, or neuropeptides such as substance $\mathrm{P}$ or neurotensin act through G-protein-coupled receptors (GPCRs) located at the plasma membrane of target neurons. The neuronal response to stimulation depends in part on the abundance of receptors at the membrane. Many in vitro experiments have shown that the subcellular localization of GPCRs, especially their availability at the membrane, is regulated by the neurochemical environment (Fonseca et al., 1995; Roettger et al., 1995; Koenig and Edwardson, 1996; Barnes et al., 1997; Koenig et al., 1997; Marvizon et al., 1997). Indeed, the stimulation of such receptors induces complex events, including internalization of the membrane-bound receptors into endocytic vesicles and their degradation and recycling to the membrane. Modifications of the quantity of receptors available at the plasma membrane and related events have been suggested to contribute to functional

\footnotetext{
Received July 6, 1999; revised Sept. 8, 1999; accepted Sept. 15, 1999.

We thank Dr. P. Ciofi (U.378 Institut National de la Santé, et de la Recherche Médicale-Institut François Magendie, 1, rue Camille Saint-Saëns, 33077 Bordeaux, France) for providing the anti- $\mu$ opiate receptor-1A. We also thank Evelyne Doudnikoff for her expert technical work, Claude Vidauporte for the photographic artwork, and the Electron Microscopy Centre of the University Victor SégalenBordeaux 2.

Correspondence should be addressed to Dr. Véronique Bernard, Centre National de la Recherche Scientifique, Unité Mixte de Recherche 5541, Laboratoire d'Histologie-Embryologie, Université Victor Ségalen-Bordeaux 2, 146 rue LéoSaignat, 33076 Bordeaux Cedex, France. E-mail: Veronique.Bernard@umr5541.ubordeaux2.fr.

Copyright (C) 1999 Society for Neuroscience $\quad 0270-6474 / 99 / 1910237-13 \$ 05.00 / 0$
}

responses to stimulation, including desensitization and resensitization (Hertel et al., 1985; Pippig et al., 1995; McDonald et al., 1998; Mundell and Kelly, 1998). The mechanisms regulating in vivo, the subcellular distribution of receptors in neurons, are still poorly understood (Bloch et al., 1999). In physiological circumstances, the abundance of receptors at the plasma membrane is the result of complex intracellular trafficking of these receptors (Koenig and Edwardson, 1997). The nature and the density of the afferent innervation seems to contribute to these regulations, as demonstrated for the somatostatin sst2A receptor (Dournaud et al., 1998). In acute conditions, receptors for various neurotransmitters (dopamine, substance $\mathrm{P}$, or opiates) have been shown to undergo subcellular redistribution after pharmacological stimulation, including translocation of the receptor from the membrane to the cytoplasm, internalization in endosomes, and recycling to the membrane (Faure et al., 1995; Sternini et al., 1996; Marvizon et al., 1997; Bernard et al., 1998; Dumartin et al., 1998; Bloch et al., 1999). By regulating the quantity of the receptors available for stimulation, such phenomena may play key roles in the neuronal response to modifications of the neurochemical environment in physiological, experimental, or pathological conditions.

To better understand the subcellular trafficking of classical neurotransmitter receptors in vivo, we have investigated if the cholinergic environment may influence the compartmentalization of ACh receptors in striatal cholinoceptive neurons in physiological and experimental conditions. The cholinergic environment may be defined by anatomical and neurochemical criteria, includ- 
ing the density of cholinergic terminals, AChE and choline acetyltransferase (ChAT) activity, density of cholinergic receptors, and choline uptake sites. ACh, which is produced by striatal cholinergic neurons, regulates the activity of various neuronal populations, including cholinergic neurons themselves (Kemel et al., 1992; Stoof et al., 1992; Bernard et al., 1993; Nisenbaum et al., 1994; Wang and McGinty, 1996a,b, 1997). In the striatum, ACh action is mediated through three G-protein-coupled muscarinic receptors expressed in several neuronal populations: in medium spiny neurons as heteroreceptors ( $\mathrm{m} 1 \mathrm{R}$ and $\mathrm{m} 4 \mathrm{R})$ and also in cholinergic neurons, as autoreceptors (m1R, m2R, and $\mathrm{m} 4 \mathrm{R}$ ) (Levey et al., 1991; Bernard et al., 1992, 1998; Hersch et al., 1994; Ince et al., 1997).

We have recently shown, using immunohistochemical approaches at light and electron microscopic levels, that the muscarinic $\mathrm{m} 2$ receptor $(\mathrm{m} 2 \mathrm{R})$ is expressed at the plasma membrane of striatal cholinergic interneurons in basal conditions and that acute cholinergic stimulation by agonists provokes $\mathrm{m} 2 \mathrm{R}$ endocytosis, degradation, and/or neosynthesis (Bernard et al., 1998). In the present study, we have first examined and quantified the subcellular distribution of $\mathrm{m} 4 \mathrm{R}$ in several striatal neuronal populations of normal animals (medium spiny neurons and cholinergic interneurons). Second, we have studied the effect of the activation of muscarinic receptors on the distribution of $\mathrm{m} 4 \mathrm{R}$ in the different neuronal compartments and their association with the different subcellular organelles.

\section{MATERIALS AND METHODS}

\section{Animals and tissue preparation}

Sprague Dawley male adult rats (Center d'élevage Janvier, Le Genest St. Isle, France; 200-300 gm) were used in this study. Environmental conditions for housing of the rats and all procedures that were performed on them were in accordance with the guidelines of the French Agriculture and Forestry Ministry (decree 87849, license 01499), with the approval of the Centre National de la Recherche Scientifique, and in accordance with the policy on the use of animals in Neuroscience research issued by the Society for Neuroscience.

The rats received the following treatments: (1) Several groups of rats were treated with a single injection of oxotremorine, a muscarinic receptor agonist (Table 1). (2) One group of rats was pretreated with atropine, a muscarinic receptor antagonist, $15 \mathrm{~min}$ before oxotremorine to block the effect of the agonist. (3) Control animals were treated with saline as a single injection or in association with oxotremorine or atropine. All drugs were injected subcutaneously $(0.1 \mathrm{ml} / 100 \mathrm{gm})$. The animals were usually euthanized $45 \mathrm{~min}$ after the last injection of each drug. To examine the time course of the effect of oxotremorine, some animals were allowed to survive from $10 \mathrm{~min}$ to $24 \mathrm{hr}$ (Table 1). All drugs were diluted in $0.9 \% \mathrm{NaCl}$. Oxotremorine-free base and atropine sulfate salt were obtained from Sigma (St. Louis, MO).
The rats were deeply anesthetized with sodium chloral hydrate and then perfused transcardially with $50-100 \mathrm{ml}$ of $0.9 \% \mathrm{NaCl}$ followed by $250 \mathrm{ml}$ of fixative consisting of $2 \%$ paraformaldehyde (PFA) with $0.2 \%$ glutaraldehyde in $0.1 \mathrm{M}$ phosphate buffer $\left(\mathrm{PB}, \mathrm{pH} 7.4,4^{\circ} \mathrm{C}\right)$ at a rate of $\sim 15 \mathrm{ml} / \mathrm{min}$. The brain was quickly removed and left overnight in $2 \%$ PFA at $4^{\circ} \mathrm{C}$. Sections from neostriatum were cut on a vibrating microtome at $\sim 70 \mu \mathrm{m}$ and collected in PBS (0.01 M phosphate, $\mathrm{pH} 7.4)$. To enhance the penetration of the immunoreagents in the pre-embedding procedures, the sections were equilibrated in a cryoprotectant solution

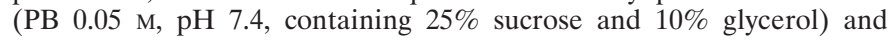
freeze-thawed by freezing in isopentane cooled in liquid nitrogen and thawing in PBS. The sections were washed and stored in PBS until use.

\section{Immunohistochemistry}

The $\mathrm{m} 4 \mathrm{R}$ was detected by immunohistochemistry using a monoclonal antibody raised in mouse against a fusion protein derived from a sequence of the receptor corresponding to the third intracytoplasmic loop [purchased from Chemicon (Temecula, CA) in collaboration with A. I. Levey]. The $\mu$-opioid receptor ( $\mu$-opiate receptor) was detected using a rabbit polyclonal antiserum (coded IS-7/15; kindly provided by Dr. P. Ciofi) raised against a human serum albumin-glutaraldehyde conjugate of a synthetic peptide corresponding to the intracytoplasmic C-t decapeptidic sequence of rat $\mu$-opiate receptor-1A (NLEAETAPLP) that is absent in rat $\mu$-opiate receptor-1B (Zimprich et al., 1995). Preabsorption of IS-7/15 with 10-6 M decapeptide totally abolished staining. The cholinergic neurons containing $\mathrm{m} 4 \mathrm{R}$ immunoreactivity were identified by their expression of ChAT. ChAT was detected using a polyclonal antibody raised in goat (Chemicon).

Immunoperoxidase detection of $m 4 R$ at the light microscopic level. Sections of striatum were treated for the detection of $\mathrm{m} 4 \mathrm{R}$ by immunoperoxidase using the tyramide signal amplification (TSA) method (New England Nuclear, Boston, MA). After perfusion-fixation as described above, $70-\mu \mathrm{m}$-thick sections were cut on a vibratome and incubated in $4 \%$ normal goat serum (NGS) for $30 \mathrm{~min}$ and then in the antibody against m4R (1:20,000), supplemented with $1 \%$ NGS for $15 \mathrm{hr}$ at room temperature (RT). The sections were then washed in PBS and incubated in goat anti-mouse IgG coupled to biotin (Amersham; 1:200 in PBS for $90 \mathrm{~min}$ ). After washing in PBS, the sections were incubated in streptavidinhorseradish peroxidase (strept-HRP) (1:100 in PBS for $30 \mathrm{~min}$ ), then in biotinyltyramide (1:50 in amplification diluent for $7 \mathrm{~min}$ ), and again in strept-HRP (1:100 in PBS for $30 \mathrm{~min})$. After washing [2× PBS, $1 \times$ Tris buffer (TB) $0.05 \mathrm{M}, \mathrm{pH} 7.6$ ], the immunoreactive sites were revealed by incubation in 3,3-diaminobenzidine (DAB; Sigma, $0.05 \%$ in TB) in the presence of $\mathrm{H}_{2} \mathrm{O}_{2}(0.0048 \%)$. The reaction was stopped by several washes in TB. The specificity of the labeling techniques was proven by the absence of $\mathrm{m} 4 \mathrm{R}$ labeling when the primary or secondary antibody was omitted. The sections were then processed for inclusion in resin and for visualization of the labeling on semithin sections.

Double detection of $m 4 R$ and neuronal markers by combination of immunogold and immunoperoxidase methods at the ultrastructural level. $\mathrm{m} 4 \mathrm{R}$ was analyzed specifically in cholinergic neurons by combining $\mathrm{m} 4 \mathrm{R}$ and ChAT detection. The $\mathrm{m} 4 \mathrm{R}$ was analyzed in medium spiny neurons of patches and matrix compartments by combining $\mathrm{m} 4 \mathrm{R}$ and $\mu$-opiate receptor detection. The $\mu$-opiate receptor immunoreactivity was specifically restricted to patch neurons (Arvidsson et al., 1995). The $\mathrm{m} 4 \mathrm{R}$ and

Table 1. Treatments and number of animals used.

\begin{tabular}{|c|c|c|c|c|}
\hline Treatment & & Dose $(\mathrm{mg} / \mathrm{kg})$ & Number of animals & Survival time \\
\hline Muscarinic agonist & Oxotremorine & 0.5 & 2 & $10 \mathrm{~min}$ \\
\hline & & 0.5 & 2 & $20 \mathrm{~min}$ \\
\hline & & 0.5 & 17 & $45 \min$ \\
\hline & & 0.5 & 2 & $1 \mathrm{hr} 30 \mathrm{~min}$ \\
\hline & & 0.5 & 2 & $3 \mathrm{hr}$ \\
\hline & & 0.5 & 1 & $7 \mathrm{hr}$ \\
\hline & & 0.5 & 2 & $24 \mathrm{hr}$ \\
\hline Blockade experiments & Atropine + oxotremorine & $5+0.5$ & 2 & $45 \mathrm{~min}$ \\
\hline Controls & Saline & 9 & 15 & $45 \mathrm{~min}$ \\
\hline & Saline + oxotremorine & $9+0.5$ & 2 & $45 \min$ \\
\hline & Atropine + saline & $5+9$ & 2 & $45 \mathrm{~min}$ \\
\hline
\end{tabular}



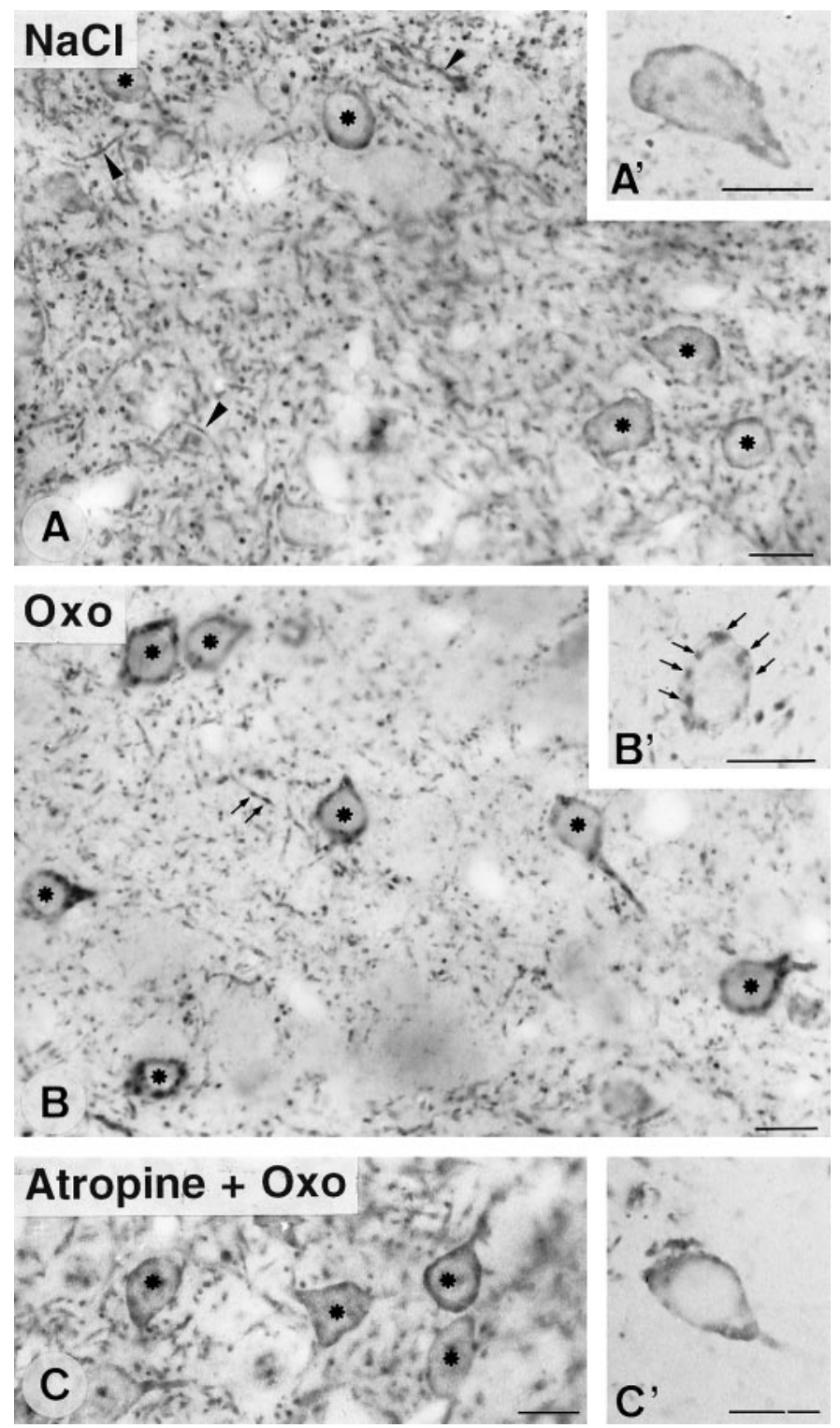

Figure 1. Cellular and subcellular distribution of m4R immunoreactivity in striatal neurons in control $\left(A, A^{\prime}\right)$, oxotremorine-treated $\left(B, B^{\prime}\right)$ rats, and rat pretreated with atropine 15 min before oxotremorine $\left(C, C^{\prime}\right)$ using the immunoperoxidase method on thick $(70 \mu \mathrm{m})(A-C)$ and semithin sections $(1 \mu \mathrm{m})\left(A^{\prime}-C^{\prime}\right)$. In control animals $\left(A, A^{\prime}\right)$, m4R immunoreactivity is detected at the membrane of some cell bodies of neurons often seen in clusters (asterisks). Immunolabeling for $\mathrm{m} 4 \mathrm{R}$ is also seen in dendrites (arrowheads), but with reduced immunoreactivity. After oxotremorine treatment $\left(B, B^{\prime}\right)$, a decrease in the amount of neuropil labeling was observed, and a strong $\mathrm{m} 4 \mathrm{R}$ immunoreactivity was detected in the cytoplasm of numerous cell bodies (asterisks). Spots of labeling are clearly identified in perikarya and in dendrites [small arrows in $B$ (dendrites) and $B^{\prime}$ (perikarya)]. The pretreatment with atropine, a muscarinic receptor antagonist, abolishes the effect of oxotremorine: immunoreactivity for $\mathrm{m} 4 \mathrm{R}$ is similar to the labeling observed in control animals $(C$, $\left.C^{\prime}\right)$. Scale bars, $10 \mu \mathrm{m}$.

ChAT or $\mu$-opiate receptor immunoreactivities were detected on the same sections by combining the pre-embedding immunogold and immunoperoxidase techniques, respectively. Sections of striatum were incubated in $4 \%$ NGS (m4R $+\mu$-opiate receptor) or normal donkey serum (NDS) (m4R + ChAT) for $30 \mathrm{~min}$ and then in a mixture of $\mathrm{m} 4 \mathrm{R}(1: 2000)$ and $\mu$-opiate receptor $(1: 2000)$ or ChAT (1:400) antibodies, supplemented with $1 \%$ NGS or NDS for $15 \mathrm{hr}$ at RT. For the simultaneous detection of $\mathrm{m} 4 \mathrm{R}$ and $\mu$-opiate receptor, the sections were then incu- bated in a mixture of goat anti-mouse IgGs conjugated to gold particles (1.4 nm diameter; Nanoprobes, Stony Brook, NY; 1:100 in PBS/BSA-C) and donkey anti-rabbit coupled to biotin (1:200) for $2 \mathrm{hr}$ in PBS/BSA-C. The sections were then washed $(3 \times$ PBS $)$ and post-fixed in $1 \%$ glutaraldehyde in PBS for $10 \mathrm{~min}$. After washing $(2 \times$ PBS; $2 \times$ sodium acetate buffer, $0.1 \mathrm{M}, \mathrm{pH} 7.0$ ), the diameter of the gold immunoparticles was increased using a silver enhancement kit (HQ silver; Nanoprobes) for 5 min at RT in the dark. The sections were finally washed in acetate buffer and in PBS and incubated in an avidin-biotin-peroxidase complex (ABC), (1:100; Vector Laboratories, Burlingame, CA) for $1.5 \mathrm{hr}$ at RT. After washing ( $2 \times$ PBS, $1 \times$ TB $0.05 \mathrm{M}, \mathrm{pH} 7.6)$, the immunoreactive sites for $\mu$-opiate receptor were revealed using DAB as above. For the double detection of $\mathrm{m} 4 \mathrm{R}$ and ChAT, the sections were first incubated in rabbit anti-goat coupled to biotin (1:200) for $90 \mathrm{~min}$ in PBS and then, after washing, in goat anti-mouse IgGs conjugated to gold particles (1:100) for $2 \mathrm{hr}$ in PBS/BSA-C. After intensification of the immunogold signal for $\mathrm{m} 4 \mathrm{R}$, the sections were incubated in $\mathrm{ABC}(1: 100)$ for $1.5 \mathrm{hr}$, and the peroxidase reaction for ChAT was revealed as described above. Some spare sections were treated for the immunogold detection of $\mathrm{m} 4 \mathrm{R}$ alone. The sections were then stored in $\mathrm{PB}$ and processed for electron microscopy.

\section{Preparation for electron microscopy}

The sections were post-fixed in osmium tetroxide $(1 \%$ in $\mathrm{PB}, 0.1 \mathrm{M}, \mathrm{pH}$ 7.4) for 10 min (immunogold or immunogold and immunoperoxidase) or 25 min (immunoperoxidase alone) at RT. After washing $(3 \times \mathrm{PB})$, they were dehydrated in an ascending series of dilutions of ethanol that included $1 \%$ uranyl acetate in $70 \%$ ethanol. They were then treated with propylene oxide (two times for $10 \mathrm{~min}$ ) and equilibrated in resin overnight (Durcupan ACM; Fluka, Buchs, Switzerland), mounted on glass slides, and cured at $60^{\circ} \mathrm{C}$ for $48 \mathrm{hr}$. Areas of interest were first visualized in the light microscope and cut out from the slide and glued to blank cylinders of resin. Blocks were cut out in $\mu$-opiate receptorimmunopositive (patches) and immunonegative (matrix) areas. By another way, ChAT-positive neurons were identified in the light microscope. The selection was made to have several ChAT-immunopositive neurons on the same block (usually four or five). The immunoreactive areas identified on thick sections were cut in semithin sections $(1-\mu \mathrm{m}-$ thick), then in ultrathin sections on a Reichert Ultracut S. Ultrathin sections were collected on pioloform-coated single slot copper grids. The sections were stained with lead citrate and examined in a Philips CM10 electron microscope.

\section{Quantitative analysis of the distribution of $m 4 R$ in striatal neuronal compartments}

The distribution of $\mathrm{m} 4 \mathrm{R}$ in different organelles: (1) of perikarya of striatal cholinergic neurons, (2) of perikarya of medium spiny neurons, and (3) of dendrites in patches and matrix in NaCl- and oxotremorinetreated animals was analyzed from immunogold-treated sections at electron microscopic level. The analysis was performed on negatives of micrographs at a final magnification of $3900 \times$ (cholinergic neurons) or $5200 \times$ (medium spiny neurons) using the Metamorph software on a personal computer (Universal Imaging, Paris, France). After scanning of the negative (Umax; software, Magic Scan, version 3.1), the image was converted into a positive picture and magnified to allow the identification of the subcellular element showing immunoparticles. The measures were performed on four $\mathrm{NaCl}$-treated and four oxotremorine-treated rats. A mean of 10 (cholinergic neurons) and 15 (medium spiny neurons) perikarya per animal and 30 dendritic profiles was analyzed. The immunoparticles were identified and counted in perikarya in association with seven subcellular compartments. Six compartments are the plasma membrane, endosome-like vesicles, multivesicular bodies, the Golgi apparatus, the endoplasmic reticulum, and the outer nuclear membrane. Some immunoparticles were classified as associated with a seventh unidentified compartment because they were associated either with no detectable organelles or with an organelle that could not be identified as one of the previous ones. The distribution of the immunoparticles in dendrites was quantified in dendrites surrounding the medium spiny neurons on the same micrographs. All positive dendrites (with more than two immunoparticles) on the picture were taken in account for the quantification. The immunoparticles were localized in association with three subcellular compartments: the plasma membrane, endosomes, and multivesicular bodies. As in perikarya, some immunoparticles could not be classified in association with one of the previous compartments. The results were expressed (1) as the percentage of immunoparticles associated with the 
Figure 2. Subcellular distribution of $\mathrm{m} 4 \mathrm{R}$ immunoreactivity in the striatum in the matrix and patches of control rats using the pre-embedding immunogold method with silver intensification. The matrix and patch areas were identified by the absence $(A)$ or presence $(B)$, respectively, of immunoreactivity for $\mu$-opiate receptor $(M O R)$, detected by the immunoperoxidase method. In $B$, the MOR immunoreaction product was visible close to the membrane of the cell body and in a dendrite $(d) . A, B$, Immunopositive cell body with an unindented nucleus $(n)$ and thin rim of cytoplasm are characteristic of striatal medium spiny neurons. The immunoparticles are associated mostly with the internal side of the plasma membrane (arrowheads). The density of immunoparticles is higher in the patches $(B)$ than in the matrix neurons $(A)$. Some immunoparticles are associated with the outer nuclear membrane (flat arrows) and the internal side of the membrane of dendrites $(d)$. Scale bars, $0.5 \mu \mathrm{m} . n$, Nucleus.
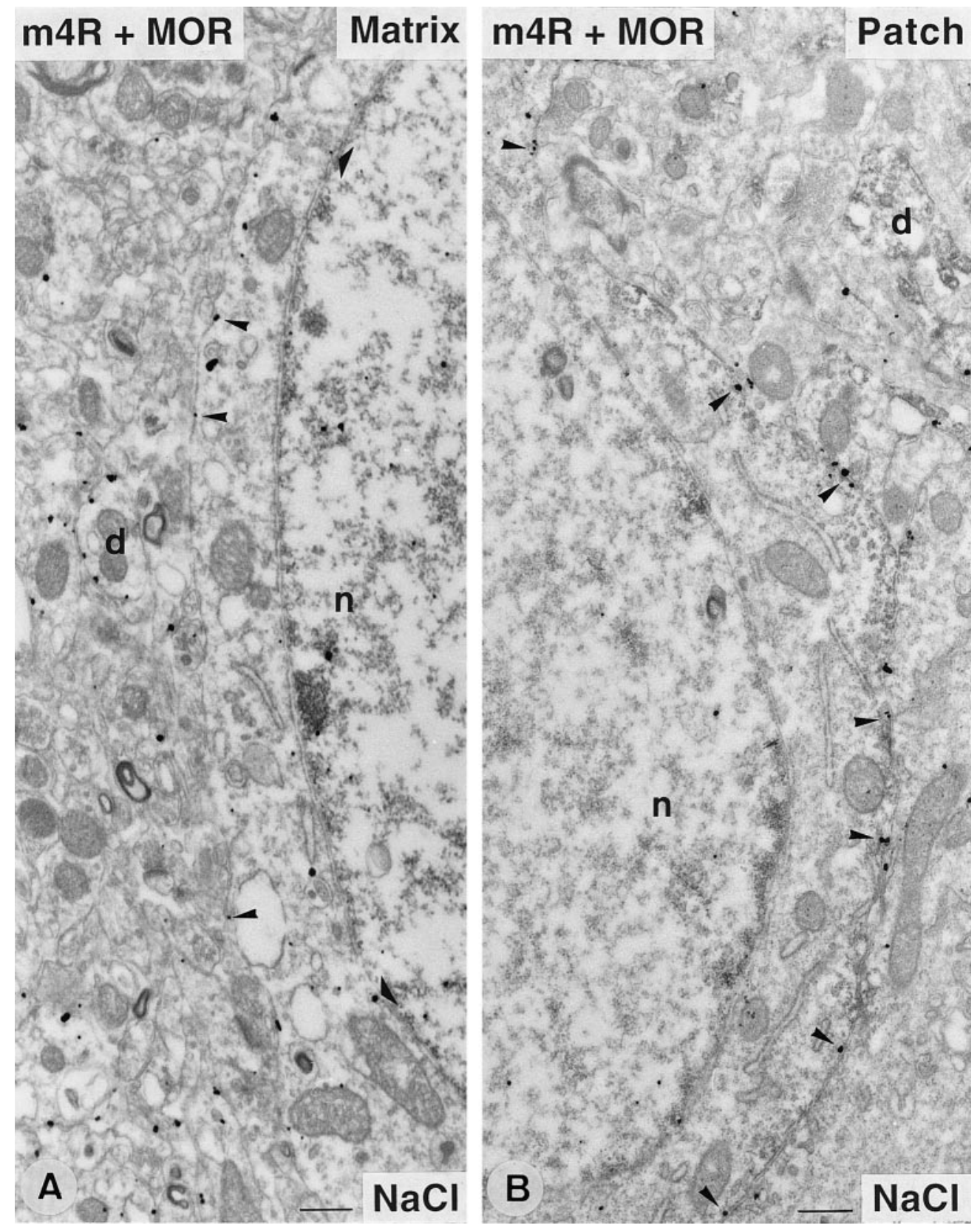

different subcellular compartments in every section of analyzed neurons in normal animals and (2) as the number of immunoparticles per plasma or nuclear membrane length (in micrometers), cytoplasmic surface (in square micrometers), mutivesicular body, or Golgi apparatus in normal and in treated rats. We assume here that the number of immunoparticles is proportional to the absolute number of $\mathrm{m} 4 \mathrm{R}$. The values from $\mathrm{NaCl}-$ and oxotremorine-treated rats were compared using a two-way ANOVA test, with treatment and striatal compartment as between-factors and within-factors, respectively. To show possible differences in values between patches and matrix, post hoc comparisons were performed using a Student's $t$ test.

\section{RESULTS}

\section{Cellular and subcellular distribution of $\mathrm{m} 4 \mathrm{R}$} immunoreactivity in the striatum in control rats

By combining several approaches of immunodetection of $\mathrm{m} 4 \mathrm{R}$ at the light and electron microscopic level, we have described three types of neurons according to the subcellular localization of m4R: (1) medium spiny neurons of the patches (identified by the pres- ence of $\mu$-opiate receptor immunoreactivity), displaying a strong $\mathrm{m} 4 \mathrm{R}$ immunolabeling at the membrane, (2) medium spiny neurons of the matrix (identified by the absence of $\mu$-opiate receptor immunoreactivity), displaying a moderate $\mathrm{m} 4 \mathrm{R}$ immunolabeling at the membrane, and (3) cholinergic interneurons, identified by ChAT immunoreactivity, showing a strong and prominent $\mathrm{m} 4 \mathrm{R}$ intracytoplasmic immunostaining.

\section{Light microscopic observations}

The normal striatum displayed intense immunoreactivity for $\mathrm{m} 4 \mathrm{R}$, as evidenced by observation of immunoperoxidase-treated sections with the light microscope (Fig. 1). Immunoreactivity for $\mathrm{m} 4 \mathrm{R}$ was detected in striatal dendrites and in numerous perikarya. These neurons were usually medium-sized (10-12 $\mu \mathrm{m}$ in diameter) with an unindented nucleus surrounded by a thin rim of cytoplasm. These neurons had thus characteristics of medium spiny neurons. Two types of labeling were detected. Most of these 

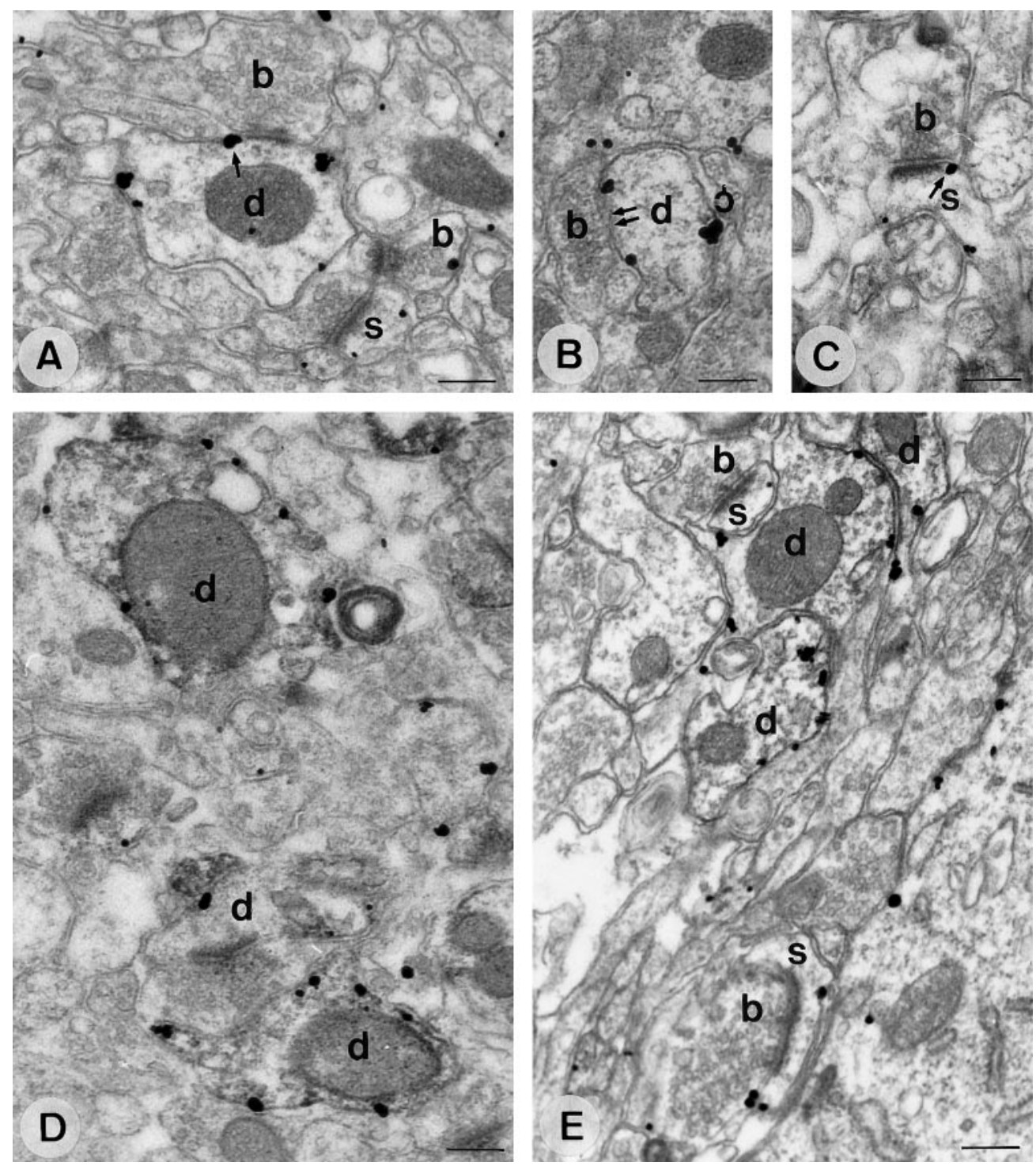

Figure 3. Subcellular distribution of m4R immunoreactivity in the striatal neuropil in the matrix $(A-C)$ and patches $(D, E)$ of control rats using the pre-embedding immunogold method with silver intensification. The matrix and patches areas were identified by the absence $(A-C)$ or presence $(\mathrm{D}, \mathrm{E})$, respectively, of immunoreactivity for MOR, detected by the immunoperoxidase method. In patches and matrix, $\mathrm{m} 4 \mathrm{R}$ immunoparticles were located mostly at the internal side of the membrane of dendrites $(d)(A, B, D, E)$ and spines $(s)(A, C, E)$. Most of the immunoparticles are located at extrasynaptic sites. Some immunoparticles are located at the edges of postsynaptic specialization of asymmetrical axodendritic (arrow) $(A)$ and axospinous synapses $(C)$, and sometimes of putative symmetrical synapses $(B)$ (double arrow). $b$, Bouton. Scale bars, $0.25 \mu \mathrm{m}$.

neurons showed a weak immunolabeling close to the plasma membrane, and thus possibly associated with it and that was often masked by the neuropil. However, other cell bodies gathered in small clusters demonstrated a strong labeling at the membrane (Fig. $1 A, A^{\prime}$ ). No obvious difference was observed in the labeling between neostriatum and the nucleus accumbens and along the rostrocaudal and dorsoventral axes. No glial labeling was observed in the striatum. Large-sized neurons corresponding to cholinergic neurons (see below), which could seldom be identified at the light microscopic level, displayed a faint m4R cytoplasmic labeling.

\section{Electron microscopic observations}

The observation at electron microscopic level confirmed that $\mathrm{m} 4 \mathrm{R}$ was mostly detected in cell bodies and dendritic shafts and spines (Figs. 2, 3). Part of the immunoparticles were associated with the internal side of plasma membranes (Figs. 2, 3). In cell bodies, dendrites, and spines, most immunoparticles were detected at extrasynaptic sites, albeit they could be localized rarely in association with postsynaptic specializations of synapses (Figs. 2, 3). Dendrites and spines displaying m4R immunoreactivity were postsynaptic to boutons forming usually asymmetrical syn- apses, and more rarely, symmetrical synapses (Fig. 3A,C,E). Very few immunoparticles for $\mathrm{m} 4 \mathrm{R}$ were visible in boutons.

Distribution of $m 4 R$ immunoreactivity in perikarya. The $\mathrm{m} 4 \mathrm{R}$ immunogold labeling was observed and quantified specifically in three types of cell bodies: (1) in $\mu$-opiate receptor immunopositive cell bodies of medium spiny neurons in patches; (2) in $\mu$-opiate receptor immunonegative cell bodies of medium spiny neurons, in the matrix (Fig. 2); and (3) in perikarya of cholinergic neurons (immunopositive for ChAT) (Fig. 4). In all these perikarya, the immunoparticles were identified and counted in association with seven subcellular compartments: plasma membrane, endosome-like vesicles, multivesicular bodies, Golgi apparatus, endoplasmic reticulum, nuclear membrane, and unidentified compartments. The endosome-like vesicles were small (100$200 \mathrm{~nm}$ in diameter), round, or irregular-shaped vesicles. The multivesicular bodies were large round vesicles $(500-600 \mathrm{~nm}$ in diameter) containing several small round-shaped vesicles with a clear content (see Fig. 7).

Medium spiny neurons. In medium spiny neurons of patches, $40 \%$ of the total number of immunoparticles were associated with the internal side of the plasma membrane. In the matrix, only 
Figure 4. Subcellular distribution of $\mathrm{m} 4 \mathrm{R}$ immunoreactivity in striatal cholinergic neurons of control rats $(A)$ or rats treated with oxotremorine (B) using pre-embedding immunogold method with silver intensification. The cholinergic neurons were identified using the presence of immunoreactivity for ChAT, detected by the immunoperoxidase method. The ChAT immunoreaction product was visible throughout the cytoplasm of the perikarya. $A$, The neuron immunopositive for ChAT and $\mathrm{m} 4 \mathrm{R}$ has a large volume of cytoplasm, one of the characteristic features of a striatal interneuron. Some immunoparticles are detected in the cytoplasm at the external surface of the endoplasmic reticulum (arrows). Immunoparticles are also associated with the Golgi apparatus $(G)$ and the external membrane of the nucleus (flat arrow). Very few immunoparticles are associated with the plasma membrane (arrowheads). B, Detail of the $\mathrm{m} 4 \mathrm{R}$ immunogold labeling in a ChATimmunopositive neuron, after treatment with oxotremorine. Most immunoparticles are clearly associated with endoplasmic reticulum lamina (arrows). Scale bars, $1 \mu \mathrm{m}$.

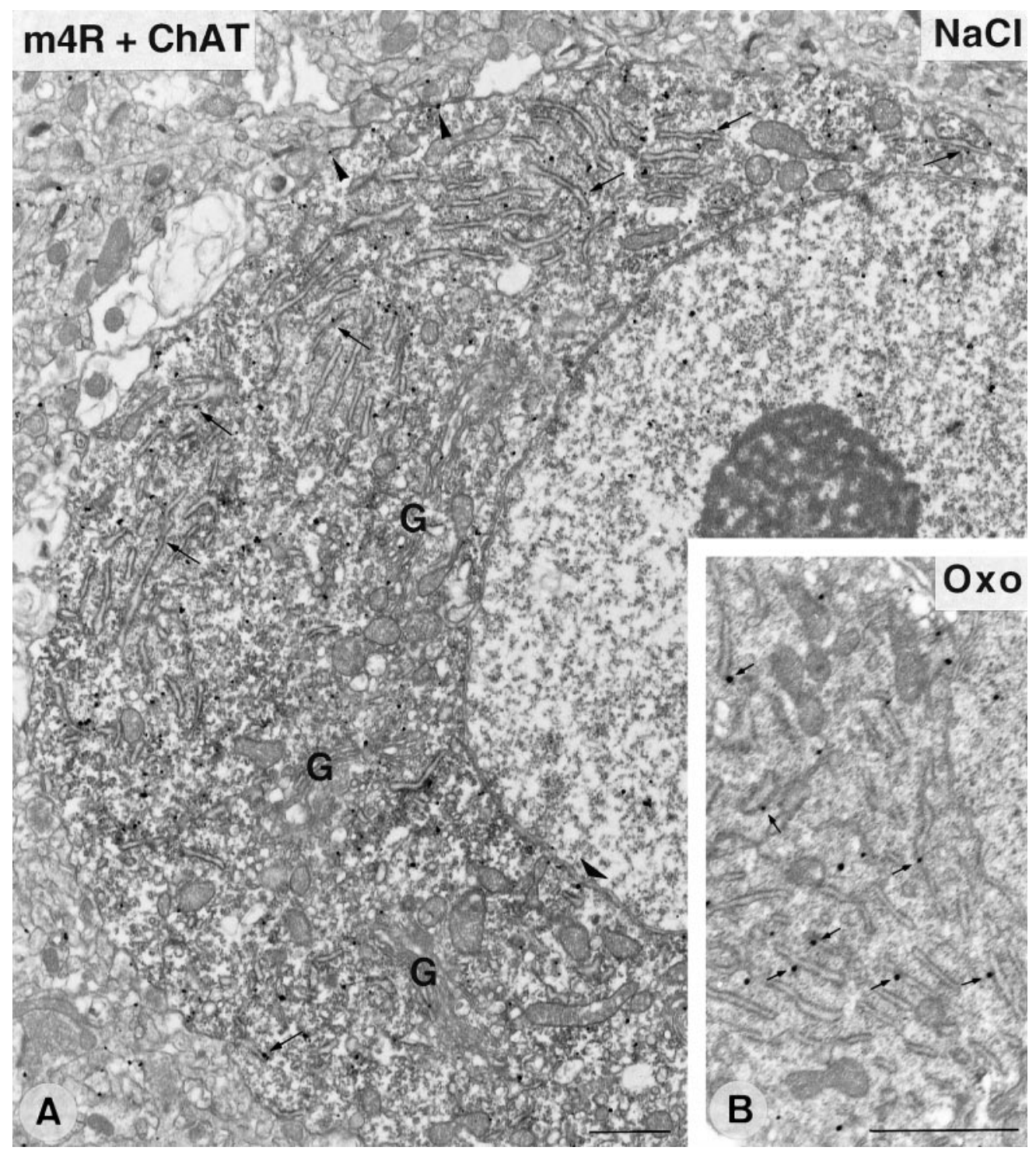

$24 \%$ of immunoparticles were associated with the membrane (Fig. 5A). The statistical analysis demonstrated a significantly higher number of immunoparticles for m4R per membrane length in patches than in matrix (see Fig. $8 A$ ). Immunoparticles were also detected in the cytoplasm in association with the endoplasmic reticulum (7\% patches; $10 \%$ matrix), endosomes (9\% patches; $11 \%$ matrix), Golgi apparatus ( $8 \%$ patches; $10 \%$ matrix), nuclear membrane (4\% patches; $4 \%$ matrix), and multivesicular bodies ( $0.2 \%$ patches; $0.4 \%$ matrix) (Figs. $2 A, 5 A)$. Thirty-three percent (patches) and $40 \%$ (matrix) of immunoparticles could not be associated with one of the previous subcellular elements (Fig. $5 A)$. No statistical difference was detected in the number of immunoparticles associated with any of these subcellular compartments in patches and matrix areas (see Fig. 8A).

Cholinergic neurons. All ChAT-immunopositive neurons that were analyzed at electron microscopic level displayed immunogold labeling for m4R (Fig. 4). In these neurons, 97\% of immunoparticles were detected in the cytoplasm. Most of the immunoparticles that were associated with an identified compartment were associated with the endoplasmic reticulum (25\%) (Figs. 4, $5 B$ ). Eleven, 4,2 . and $0.2 \%$ of immunoparticles were associated with Golgi apparatus, endosomes, nuclear membrane, and mul- tivesicular bodies, respectively (Figs. 4, 5B). Fifty-six percent of immunoparticles could not be located in association with any cytoplasmic compartment (Fig. $5 B$ ). Only $3 \%$ of the total number of immunoparticles were associated with the plasma membrane (Figs. 4A, 5B).

Distribution of $m 4 R$ immunoreactivity in dendrites. The $\mathrm{m} 4 \mathrm{R}$ immunogold labeling was observed and quantified in dendrites in patches and matrix areas (Figs. 3, $5 C$ ). In view of the density of medium spiny neurons in striatum ( $>90 \%$ of striatal neurons), most of the labeled dendrites that we identified were probably dendrites of medium spiny neurons. The immunoparticles were identified and counted in association with four subcellular compartments: plasma membrane, endosome-like vesicles, multivesicular bodies, and unidentified compartments (Fig. 5C). Most of the labeling was associated with the plasma membrane in patches $(83 \%)$ and matrix (89\%) neurons. Eight percent (patches) and $5 \%$ (matrix) of immunoparticles were detected in the cytoplasm in association with endosome-like vesicles (Fig. $5 \mathrm{C}$ ). Nine percent (patches) and 6\% (matrix) of immunoparticles could not be detected in association with one of the previous compartments. No significant difference was shown between values from patches and matrix (see Fig. 9). 


\section{Subcellular distribution of $\mathrm{m} 4 \mathrm{R}$ in striatal neurons of control rats}

A. Perikarya of medium spiny neurons

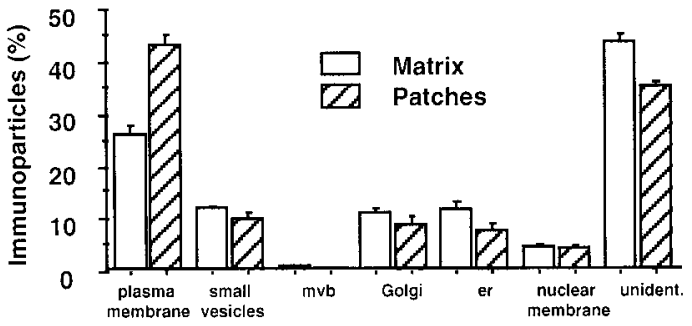

B. Perikarya of cholinergic neurons

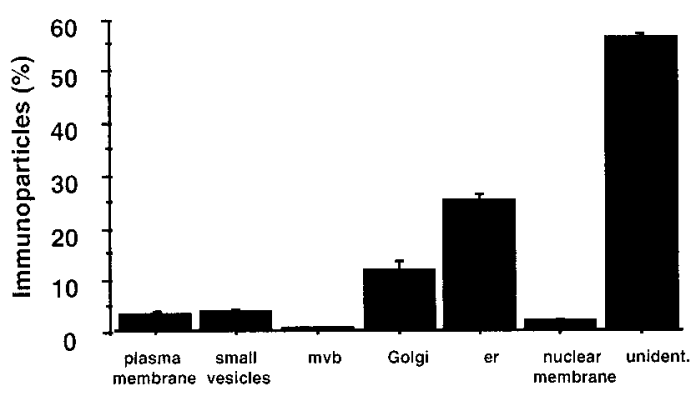

C. Dendrites

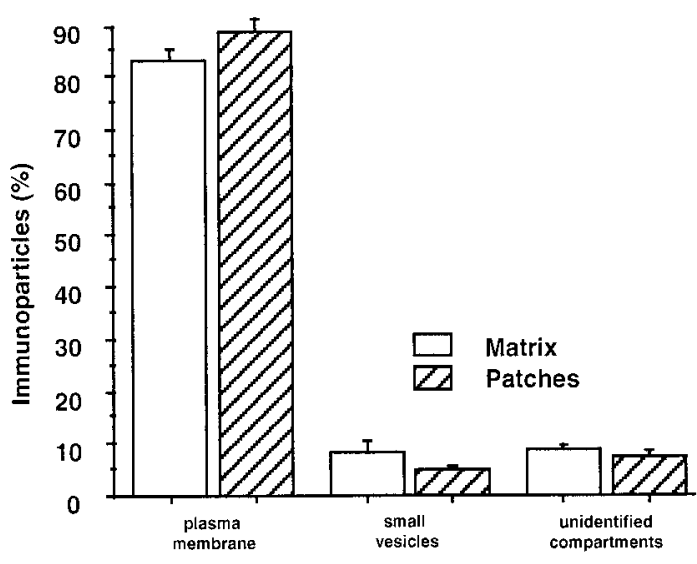

Figure 5. Quantitative analysis of the subcellular distribution of $\mathrm{m} 4 \mathrm{R}$ in the striatum of control rats using pre-embedding immunogold method with silver intensification. Proportion of immunoparticles associated with different subcellular neuronal compartments in perikarya of medium spiny neurons $(A)$ and cholinergic neurons $(B)$, and in dendrites $(C)$. For each cell body or dendrite, the number of immunoparticles associated with each compartment was counted, and the proportion in relation to the total number was calculated. Data are the result of countings in four control rats (15 medium spiny neurons, 10 medium spiny neurons, and 30 dendrites per animal). In medium spiny neurons $(A)$, of the immunoparticles that are associated with an identified compartment, most of them are preferentially located at the plasma membrane, whereas in cholinergic neurons $(B)$, they are mostly associated with the endoplasmic reticulum (er). The proportion of immunoparticles at the membrane is much higher in MOR + areas (patches) than in MOR - (matrix) areas. In the cytoplasm, the immunoparticles are mostly detected in association with small vesicles, the Golgi apparatus, and the endoplasmic reticulum in medium spiny neurons and with small vesicles and the Golgi apparatus in cholinergic neurons. In both types of neurons, a small proportion of immunoparticles are associated with multivesicular bodies $(m v b)$ and the outer nuclear membrane. Some immunoparticles are not seen in association with any of an identified compartment. In dendrites $(C)$, most of immunoparticles in matrix and patches are associated with the membrane, and only a small part are detected in association with small vesicles and with unidentified compartments.
Control for specificity of the immunohistochemical labeling. The specificity of the labeling techniques was proven by the following data: (1) the cellular localizations were in agreement with the results previously described by immunohistochemistry using an antibody against the same $\mathrm{m} 4 \mathrm{R}$ or by in situ hybridization (Bernard et al., 1992; Hersch et al., 1994). (2) The localization of immunoparticles for $\mathrm{m} 4 \mathrm{R}$ on the internal side of the plasma membrane was in agreement with the localization of the epitope included in the fusion protein (third intracytoplasmic loop). (3) There was an absence of m4R labeling at light microscopic level when the primary or secondary antibody was omitted. (4) We have checked in double-labeling experiments ( $\mu$-opiate receptor $+\mathrm{m} 4 \mathrm{R}$ ) that the immunoperoxidase procedure to detect $\mu$-opiate receptor did not interfere with the immunogold labeling for $\mathrm{m} 4 \mathrm{R}$. For that, we have checked in one control animal that the subcellular distribution of m4R did not differ statistically in double- and in single-labeling experiments.

\section{Cellular and subcellular distribution of $\mathrm{m} 4 \mathrm{R}$ immunoreactivity in the striatum after treatment with oxotremorine}

The observations of the labeling immunoperoxidase- and immunogold-reacted sections at light microscopic level showed dramatic modifications of the distribution of $\mathrm{m} 4 \mathrm{R}$ immunoreactivity in medium spiny neurons; a decrease in the amount of neuropil labeling was observed and an intense punctiform labeling appeared in the cytoplasm of all immunoreactive cell bodies and their dendrites (Fig. $1 B, B^{\prime}$ ). An intracytoplasmic dotty labeling was detectable as early as 20 min after injection of oxotremorine with a faint intensity, was intense at $45 \mathrm{~min}, 1 \mathrm{hr} 30 \mathrm{~min}$, and returned weak at $3 \mathrm{hr}$ after injection. Five, 7, and $24 \mathrm{hr}$ after injection, m4R immunoreactivity was similar to the labeling observed in control animals (Fig. $2 F, G$ ). These immunoreactive puncta probably correspond to labeled endosomes seen in the electron microscopic level (Figs. 6, 7). Pretreatment of rats with atropine, a muscarinic receptor antagonist, completely abolished the effect of oxotremorine on m4R immunoreactivity (Fig. $\left.1 C, C^{\prime}\right)$.

\section{Perikarya of medium spiny neurons}

The analysis at electron microscopic level confirmed dramatic changes in the subcellular localization of m4R. It demonstrated an important decrease of the density of immunoparticles located at the plasma membrane of medium spiny neurons and modifications of the distribution of immunoreactivity in the cytoplasm in oxotremorine-treated rats compared to control animals, especially the appearance of numerous labeled endosome-like vesicles (Fig. 6). The quantitative analysis demonstrated indeed a significant decrease of the number of immunoparticles per plasma membrane length in patches $(-55 \%)($ Fig. $8 A)$. There was also a decrease of the density of $\mathrm{m} 4 \mathrm{R}$ immunoparticles at the membrane of cell bodies of matrix $(-34 \%)$, but this was not statistically significant. The total number of immunoparticles per surface of cytoplasm significantly increased $(p<0.01)$ after treatment ( $+37 \%$ patches; $+39 \%$ matrix). A strong and significant increase was detected for the number of particles associated with the endosome-like vesicles $(+335 \%$ patches; $+327 \%$ matrix $)$. There was also increased labeling associated with the Golgi apparatus ( $+40 \%$ patches; $+41 \%$ matrix). The proportion of immunopositive multivesicular bodies significantly increased $(+60 \%$ patches; $+154 \%$ matrix). There were no significant differences in the number of immunoparticles per positive multivesicular body 
Figure 6. Subcellular distribution of $\mathrm{m} 4 \mathrm{R}$ immunoreactivity in the striatum in the matrix and patches of oxotremorine-treated rats using the pre-embedding immunogold method with silver intensification. The matrix and patches areas were identified using the absence $(B)$ or presence $(C)$ of $\mu$-opiate receptor immunoreactivity, respectively, detected by the immunoperoxidase method. In $C$, the $\mu$-opiate receptor immunoreaction product was visible in a dendrite $(d) . B, C$, Immunopositive cell body with an unindented nucleus $(n)$ and a thin rim of cytoplasm are characteristic of striatal medium spiny neurons. Numerous immunoparticles are detected in the cytoplasm in association with small vesicles ( $a r$ rows). $A, D$, Details of the frame in $B$ and $C$, respectively, showing endosome-like vesicles having immunoparticles associated with them. Some immunoparticles are associated with the plasma membrane (arrowheads) and with endoplasmic reticulum (flat arrow). Scale bars: $A, D, 0.2 \mu \mathrm{m} ; B, C$, $0.5 \mu \mathrm{m}$.
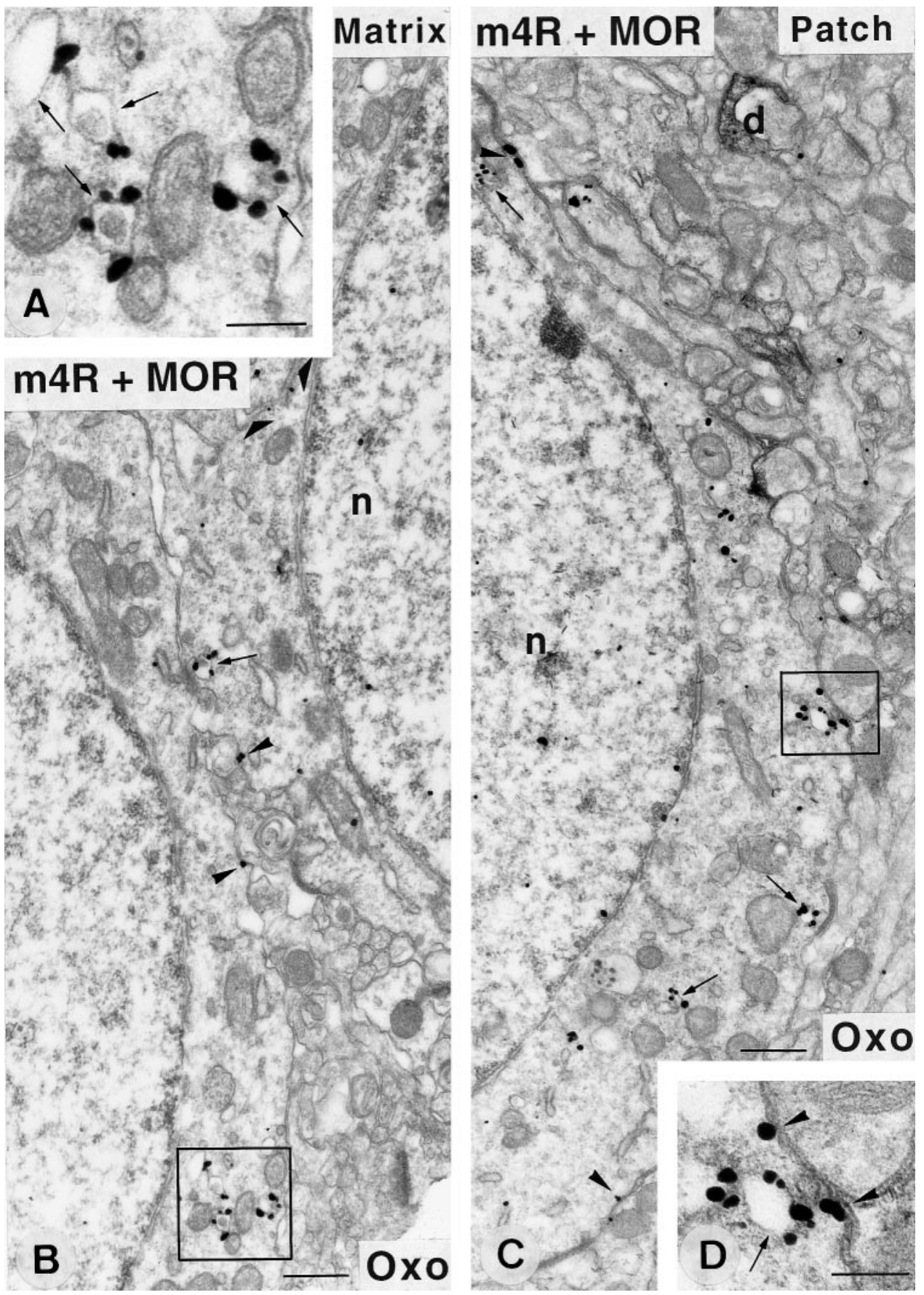

( $+29 \%$ patches; $+36 \%$ matrix $)$. No significant difference was shown, after treatment, in the percentage of immunoparticles associated with the endoplasmic reticulum, with the nuclear membrane, or with unidentified organelles (Fig. $8 A$ ). These results should be read keeping in mind that the baseline of immunoreactivity varies in control animals from one subcellular compartment to another, as seen in Figure 5.

\section{Perikarya of ChAT-immunopositive neurons}

The statistical analysis did not demonstrate any modification of the subcellular distribution of $\mathrm{m} 4 \mathrm{R}$ immunoreactivity in cholinergic neurons (Fig. 8B).

\section{Dendrites}

The observation at electron microscopic level demonstrated a decrease of the density of immunoparticles located at the plasma membrane of dendritic shafts and a modification of the distribution of immunoreactivity in the cytoplasm of the dendrites in oxotremorine-treated rats as compared to control animals (Fig. 7). The quantitative analysis demonstrated indeed a decrease of the relative abundance of immunoparticles at the plasma membrane in patches $(-54 \%)$ and matrix $(-54 \%)$ (Fig. 9). Moreover, the total number of particles significantly increased in the cytoplasm $(p<0.001)(+329 \%$ patches; $+296 \%$ matrix $)$. A very strong increase was detected for the frequency of particles asso- 


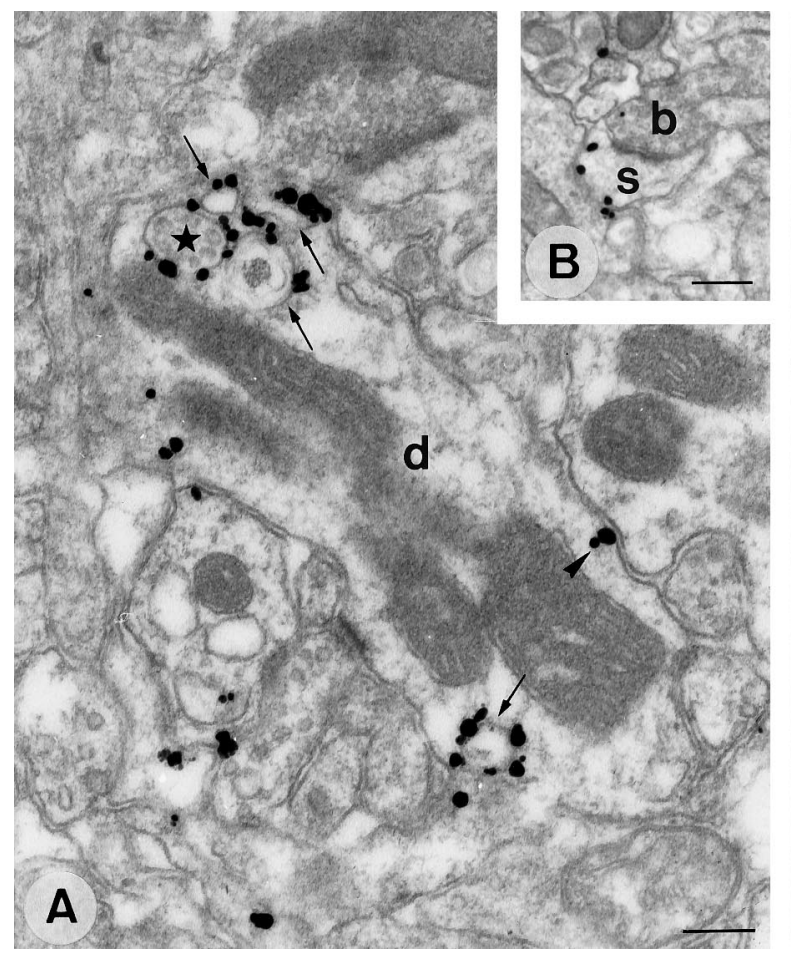

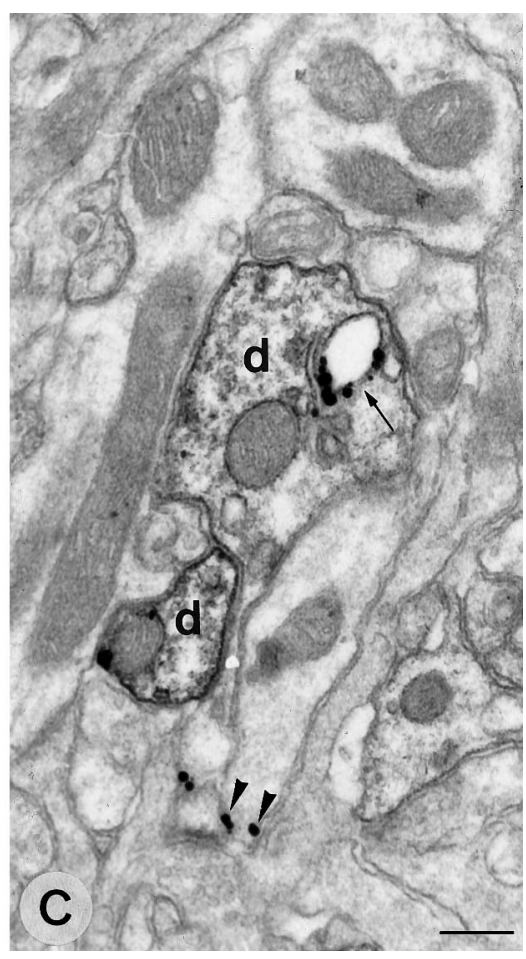

Figure 7. Subcellular distribution of m4R immunoreactivity in the striatal neuropil in the matrix and patches of oxotremorine-rats using the preembedding immunogold method with silver intensification. The matrix and patch areas were identified using the absence $(A, B)$ or presence $(C)$ of immunoreactivity for $\mu$-opiate receptor, respectively, detected by the immunoperoxidase method $(C, d)$. Most of $\mathrm{m} 4 \mathrm{R}$ immunoparticles were detected in the cytoplasm of the dendrites in association with endosome-like vesicles $(A, C$, arrows). Immunoparticles for $\mathrm{m} 4 \mathrm{R}$ were also detected in association with a multivesicular body in a dendrite $(A$, star). Some immunoparticles were located at the membrane of dendrites $(A, C)$ and a spine $(B)$ (arrowheads in dendrites). Scale bars, $0.25 \mu \mathrm{m}$. ciated with the endosome-like vesicles $(+914 \%$ patches; $+359 \%$ matrix). In dendrites, very few multivesicular bodies were seen. The m4R immunoparticles associated with unidentified compartments also significantly increased in patches $(+22 \%)$ and matrix $(+77 \%)$ areas.

\section{DISCUSSION}

We report here that the cholinergic environment influences the subcellular compartmentalization of $\mathrm{m} 4 \mathrm{R}$ in striatal neurons in physiological and experimental circumstances. In control animals, $\mathrm{m} 4 \mathrm{R}$ is mainly located as expected at the plasma membrane of perikarya and dendrites of medium spiny neurons. In contrast, in cholinergic neurons, $\mathrm{m} 4 \mathrm{R}$ is detected mostly in the cytoplasm at its sites of synthesis. The quantitative analysis at the electron microscopic level revealed a greater density of m4R at the membrane of medium spiny neurons in patches than in matrix, areas known to display low and high cholinergic activity, respectively. Oxotremorine induces internalization of $\mathrm{m} 4 \mathrm{R}$ in medium spiny neurons but has no effect on the subcellular distribution of $\mathrm{m} 4 \mathrm{R}$ in cholinergic neurons. The quantification demonstrated a decrease of the receptor at the plasma membrane of medium spiny neurons in oxotremorine-treated rats. Concurrently, the m4R immunolabeling increased in the cytoplasm, strongly in endosome-like vesicles, and more weakly in multivesicular bodies and Golgi apparatus.

\section{Availability of $\mathrm{m} 4 \mathrm{R}$ at the plasma membrane of striatal neurons in basal conditions}

Our results confirm and expand previous data demonstrating $\mathrm{m} 4 \mathrm{R}$ expression in different classes of striatal neurons (Levey et al., 1991; Bernard et al., 1992; Hersch et al., 1994; Ince et al., 1997). Light and electron microscopic observations revealed that several types of neurons displayed m4R immunoreactivity: (1) medium-sized spiny neurons, previously identified as neurons producing substance P or enkephalins (Bernard et al., 1992); and
(2) large-sized neurons, identified as cholinergic aspiny interneurons.

We demonstrate here that in basal conditions, a same GPCR may display distinct subcellular localization according to the type of neuron that expresses it (Fig. 10). We have identified three conditions with respect to the subcellular localization of m4R: (1) medium spiny neurons in patches with a high density of $\mathrm{m} 4 \mathrm{R}$ at the membrane, (2) medium spiny neurons in matrix with a moderate density of $\mathrm{m} 4 \mathrm{R}$ at the membrane, and (3) cholinergic neurons with almost no m4R associated with the membrane of cell bodies, but with a high $\mathrm{m} 4 \mathrm{R}$ density in the cytoplasm. This is of particular interest if we assume that GPCRs are expected to be located at the plasma membrane to mediate neurotransmission and that the efficiency of the neuronal response to stimulation depends on the abundance of receptors at the plasma membrane.

\section{Localization of $m 4 R$ at the membrane of medium spiny neurons}

In our model, the difference of abundance of $\mathrm{m} 4 \mathrm{R}$ at the membrane of cell bodies depending on the neuronal type may be related to differences in the cholinergic microenvironment of each neuron. Indeed, immunohistochemical studies demonstrated that the density of cholinergic axons and terminals was greater in striosomes than in matrix (Graybiel et al., 1986; Hirsch et al., 1989). Moreover, the matrix displays high acetylcholinesterase activity, in contrast with patches (Graybiel and Ragsdale, 1978). The matrix was also shown to display more affinity choline uptake sites than patches (Lowenstein et al., 1989). Taken together, these data suggest that the cholinergic activity is quantitatively more intense in the matrix than in the patches of normal animals. This suggests that there may be a correlation between the density of $\mathrm{m} 4 \mathrm{R}$ at the plasma membrane of cholinoceptive medium spiny neurons and the cholinergic tone. The more the cholinergic activity is high, the less ACh receptors are exposed at the membrane, and vice versa. This suggests also that in physiological 
Figure 8. Quantitative analysis of the subcellular distribution of $\mathrm{m} 4 \mathrm{R}$ in the striatum of control rats and rats treated with oxotremorine using pre-embedding immunogold method with silver intensification. Effect of the treatment with oxotremorine on the localization of $\mathrm{m} 4 \mathrm{R}$ immunoparticles in cell bodies of striatal medium spiny $(A)$ and cholinergic $(B)$ neurons. For each neuron, the number of immunoparticles associated with each compartment was counted in relation to the membrane length (in micrometers) for the plasma and nuclear membrane, to the surface of cytoplasm (in square micrometers) for small vesicles, the endoplasmic reticulum $(e r)$, and the unidentified compartment (unident.). For Golgi apparatus, the values are expressed as the number of immunoparticles per total number Golgi apparatus. For the multivesicular bodies $(m v b)$, the values are expressed as the number of immunopositive multivesicular bodies per total number of multivesicular bodies. Data are the result of countings in four control rats and four treated rats in $\sim 15$ medium spiny and 10 cholinergic neurons per animal. To be able to compare the oxotremorine effect on the quantity of $\mathrm{m} 4 \mathrm{R}$ in different subcellular compartments, the results are expressed in relation to an arbitrary unit 100 of the control values in matrix. In medium spiny neurons $(A)$, the statistical analysis (two-way ANOVA test, followed by Student's $t$ test) shows a significant difference in the labeling at the plasma membrane between control and treated rats $(p<0.01)$ and an interaction between treatment and striatal compartment $(p<0.01)$. The post hoc comparisons demonstrate a higher density of immunoparticles at the membrane in control patches than in control matrix $(p<0.05)$ and in control patches than in treated patches $(p<0.01)$. The analysis demonstrates an strong increase in the labeling in small vesicles $(p<0.0001)$ and a moderate increase in multivesicular bodies and Golgi apparatus $(p<$ $0.05)$, without interaction between treatment and striatal compartment. No modification of the labeling was detected in the other neuronal compartments. In cholinergic neurons $(B)$, no modification of the labeling was detected in any of the neuronal compartment.

circumstances, high levels of ACh in matrix may chronically downregulate membrane-associated receptors. These phenomena of downregulation in matrix may result of internalization of $\mathrm{m} 4 \mathrm{R}$ induced by their overstimulation by ACh. This is supported by our data demonstrating that the stimulation of muscarinic receptors induces internalization of $\mathrm{m} 4 \mathrm{R}$ in endosomes.

\section{Localization of $m 4 R$ in the cytoplasm of cholinergic neurons}

In contrast with medium spiny neurons, m4Rs are rarely detected at putative active sites (plasma membrane), but are stored mainly in basal conditions in the cytoplasm of cholinergic neurons, especially at the sites of synthesis. These m4Rs associated with the endoplasmic reticulum and the Golgi apparatus are probably receptors in the process of synthesis before being targeted to the membrane and are thus unlikely functional. This suggests that the cholinergic environment tonically downregulates $\mathrm{m} 4 \mathrm{R}$ in these neurons. Our results are in agreement with data showing that in regions with a dense somatostatinergic innervation, the somatostatin receptor sst2A displays a preferential cytoplasmic localization (Dournaud et al., 1998). In another way, in mice displaying dopaminergic overactivity caused by the knock-out of the dopamine transporter gene (Giros et al., 1996), the dopamine D1 receptor, which is located at the membrane of dopaminoceptive neurons in normal conditions, accumulates in the cytoplasm at its sites of synthesis (Dumartin et al., 2000).

The m4Rs synthesized in cholinergic neurons may also be addressed to sites of the membrane that, for technical limitations, we cannot identify in this study, e.g., at the membrane of dendrites or of the postsynaptic specialization as suggested for subunits of the channel AMPA and NMDA receptors (Bernard et al., 1997; Bernard and Bolam, 1998).

\section{Effect of the stimulation of muscarinic receptors on the subcellular distribution of $\mathrm{m} 4 \mathrm{R}$ in striatal neurons}

We report here that the stimulation of muscarinic receptors induced dramatic modifications of the subcellular distribution of $\mathrm{m} 4 \mathrm{R}$ in medium spiny neurons. The quantitative analysis at subcellular level demonstrates a decrease of the abundance of $\mathrm{m} 4 \mathrm{R}$ at the membrane of perikarya and dendrites of medium spiny neurons in patches and matrix, although the decrease was not significant in cell bodies in matrix. In parallel, we have shown a strong increase of the $\mathrm{m} 4 \mathrm{R}$ immunolabeling in association with 


\section{Subcellular distribution of $\mathrm{m} 4 \mathrm{R}$ in striatal dendrites}

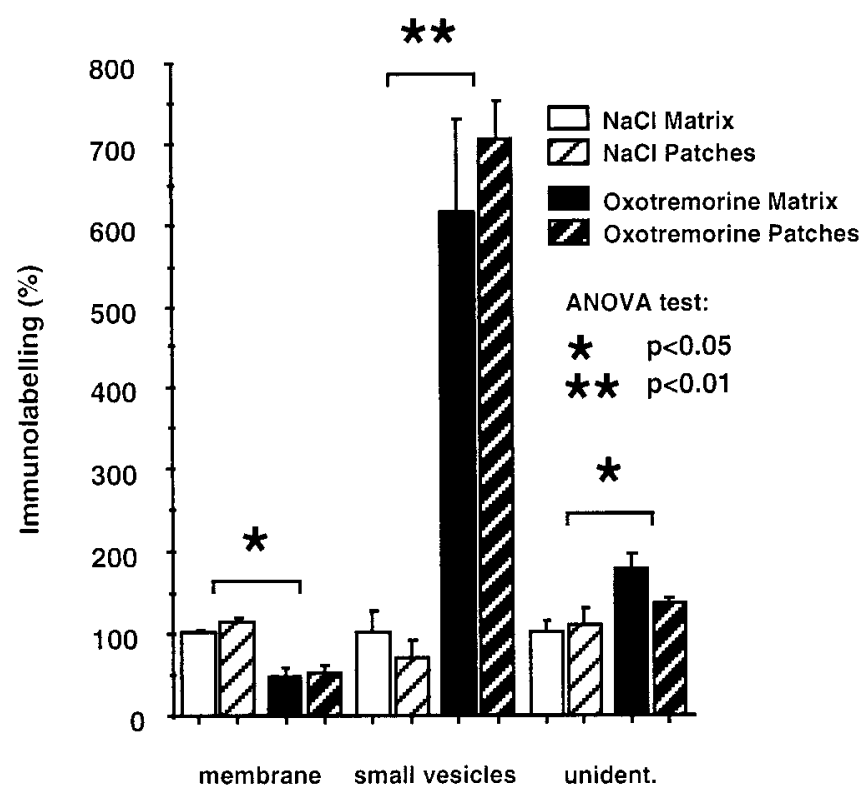

Figure 9. Quantitative analysis of the subcellular distribution of $\mathrm{m} 4 \mathrm{R}$ in the striatal dendrites of control rats and rats treated with oxotremorine, in $\mathrm{MOR}+$ areas (patches) and in MOR- (matrix) areas, using preembedding immunogold method with silver intensification. To be able to compare the oxotremorine effect on the quantity of $\mathrm{m} 4 \mathrm{R}$ in different subcellular compartments, the results are expressed in relation to an arbitrary unit 100 of the control values in matrix. For each dendrite, the number of immunoparticles associated with each compartment was counted in relation to the plasma membrane length (in micrometers), to the surface of cytoplasm (in square micrometers) for small vesicles and the unidentified compartment. The statistical analysis (two-way ANOVA test, followed by Student's $t$ test) demonstrates a significant decrease in the labeling associated with the plasma membrane $(p<0.05)$ and a very strong increase in the labeling associated with small vesicles $(p<0.01)$. A moderate increase was detected for the $\mathrm{m} 4 \mathrm{R}$ immunolabeling associated with unidentified compartments $(p<0.05)$. No interaction between treatment and striatal compartment was shown.

endosomes both in perikarya and dendrites. This suggests that the stimulation of muscarinic receptors provokes internalization of membrane-bound $\mathrm{m} 4 \mathrm{R}$ through endocytosis. Endocytotic mechanisms of neurotransmitter receptors after activation have been widely described in vitro (Koenig and Edwardson, 1997), including for muscarinic receptors (Koenig and Edwardson, 1996; Barnes et al., 1997; Vogler et al., 1999). We have recently demonstrated that $\mathrm{m} 2 \mathrm{Rs}$ also undergo endocytosis in striatal cholinergic neurons after stimulation by oxotremorine in vivo (Bernard et al., 1998). We report here that the same stimulation induces endocytosis of another muscarinic receptor, m4R, in another type of neuron, i.e., medium spiny neurons. However, in contrast with $\mathrm{m} 2 \mathrm{R}$, the stimulation does not modify the subcellular compartmentalization of $\mathrm{m} 4 \mathrm{R}$ in cholinergic neurons. This was expected because this receptor is not exposed, in contrast with $\mathrm{m} 2 \mathrm{R}$, to the membrane in basal conditions and is therefore probably not functional. Nevertheless, we cannot exclude that endocytosis occurs specifically in dendrites of cholinergic neurons that we could not identify here.

In dendrites of patches and matrix, we have also shown a decrease of $\mathrm{m} 4 \mathrm{R}$ at the membrane and a high increase of the

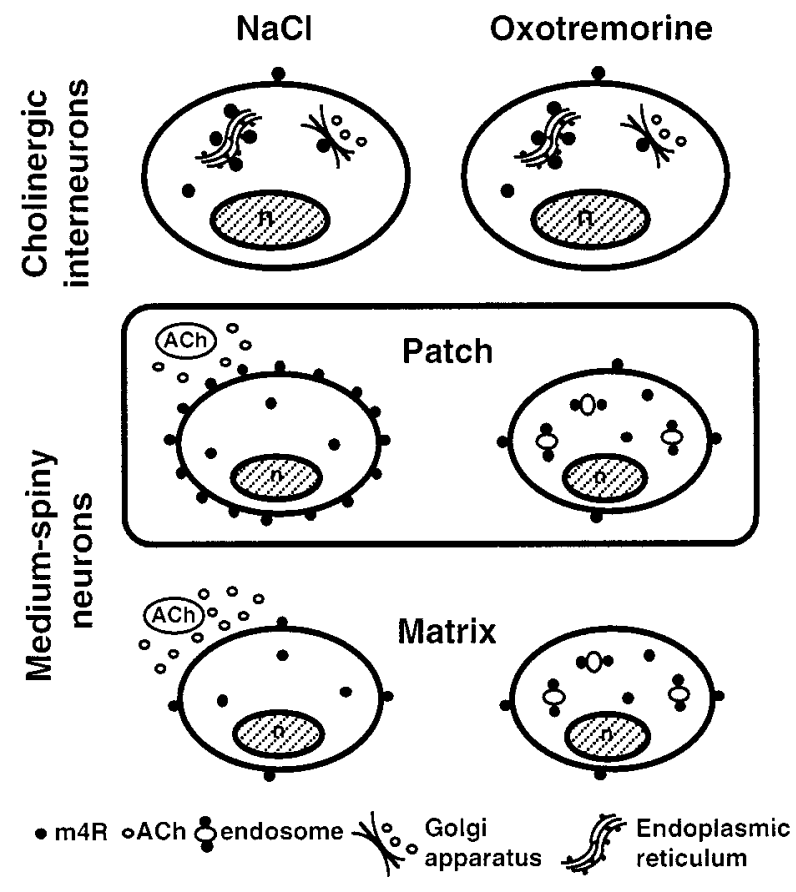

Figure 10. Schematic representation of the subcellular distribution of $\mathrm{m} 4 \mathrm{R}$ in perikarya of striatal neurons. Three conditions with respect to the subcellular localization of $\mathrm{m} 4 \mathrm{R}$ have been described: (1) cholinergic neurons with almost no $\mathrm{m} 4 \mathrm{R}$ associated with the plasma membrane, but with a high $\mathrm{m} 4 \mathrm{R}$ density in the cytoplasm in association with endoplasmic reticulum and Golgi apparatus, (2) medium spiny neurons with a high density of $\mathrm{m} 4 \mathrm{R}$ at the membrane in patches (displaying low cholinergic activity), and (3) medium spiny neurons with a moderate density of m4R at the membrane in matrix (displaying high cholinergic activity). After treatment with oxotremorine, the abundance of $\mathrm{m} 4 \mathrm{R}$ at the membrane of medium spiny neurons decreases in patches but not in matrix. In parallel, numerous $\mathrm{m} 4 \mathrm{Rs}$ are detected in association with endosomes in the cytoplasm of medium spiny neurons in both compartments. The m4R distribution in cholinergic neurons is not modified by the treatment. $n$, Nucleus.

quantity of receptors associated with endosomes; suggesting that endocytosis occurs all along the somatodendritic field. In perikarya of the matrix area, the decrease of the abundance of $\mathrm{m} 4 \mathrm{R}$ at the membrane after stimulation is not statistically significant, whereas we show a strong increase of the quantity of $\mathrm{m} 4 \mathrm{R}$ associated with endosomes. This may be explained by the fact that part of endosomes in perikarya originate in dendrites and are transported to cell bodies. This is supported by data showing that early endosomes are predominantly located in dendrites, in contrast with late endosomes that are present in cell bodies in hippocampal cultured neurons, in basal conditions (Parton et al., 1992). This is also in agreement with the internalization of the neurotensin receptor and its ligand in endosomes that are mobilized from dendrites and accumulate in perikarya (Faure et al., 1995). These results suggest complex relationships between the different neuronal compartments that contribute to regulate overall neuronal quantity of membrane-bound receptors (Bloch et al., 1999).

Our data also demonstrate that endocytosis is associated with other intracellular events induced by the stimulation of m4R. Indeed, we have also demonstrated an increase of m4R associated with multivesicular bodies and the Golgi apparatus in cell bodies. Because multivesicular bodies are thought to have function of lysosomes, part of internalized $\mathrm{m} 4 \mathrm{R}$ may thus undergo a process of degradation (van Deurs et al., 1993). Moreover, maturation of 
$\mathrm{m} 4 \mathrm{R}$ in Golgi apparatus may be a quick event consecutive to stimulation to compensate the loss of $\mathrm{m} 4 \mathrm{R}$ at the membrane by maturation of new receptors. These two phenomena seem to be a classical reaction, at least in this type of stimulation, because they were observed also for m2R (Bernard et al., 1998).

\section{Functional implications}

The present results demonstrates that in vivo, in physiological and experimental conditions, the neurochemical environment regulates the subcellular localization of neurotransmitter receptors, especially the abundance of these receptors at the plasma membrane. The regulation of the distribution of neurotransmitter receptors may be a means to adapt the response of the postsynaptic neuron to variations of the neurochemical environment, including modifications of the levels of the endogenous ligand in basal conditions. In humans, such a regulation may occur in pathology. The motor disorders observed in Parkinson's disease are thought to be caused, at least in part, by cholinergic overactivity (Calne, 1993). The modification of the availability of muscarinic receptors that may result of the overstimulation of muscarinic receptors on efferent neurons could modify the function of these neurons, including excitability, neurotransmitter synthesis or release, or gene expression. Availability of receptors and thus, the transmission of the neuronal message, may also be modified by molecules interacting with these receptors, as suggested by the fact that L-dopa provokes internalization of D1R in Parkinson's disease patients (Muriel et al., 1999). The same methodology could be expanded to other brain areas, which could help to better understand the physiological relevance of regulations of the subcellular localization of receptors and the role of perturbations of the neuronal activity caused by cholinergic dysfunctions, especially in the cortex in Alzheimer's disease.

\section{REFERENCES}

Arvidsson U, Riedl M, Chakrabarti S, Lee JH, Nakano AH, Dado RJ, Loh HH, Law PY, Wessendorf MW, Elde R (1995) Distribution and targeting of a $\mu$-opioid receptor (MOR1) in brain and spinal cord. J Neurosci 15:3328-3341.

Barnes PJ, Haddad EB, Rousell J (1997) Regulation of muscarinic M2 receptors. Life Sci 60:1015-1021.

Bernard V, Bolam JP (1998) Subcellular and subsynaptic distribution of the NR1 subunit of the NMDA receptor in the neostriatum and globus pallidus of the rat: co-localization at synapses with the GluR2/3 subunit of the AMPA receptor. Eur J Neurosci 10:3721-3736.

Bernard V, Normand E, Bloch B (1992) Phenotypical characterization of the rat striatal neurons expressing muscarinic receptor genes. J Neurosci 12:3591-3600.

Bernard V, Dumartin B, Lamy E, Bloch B (1993) Fos immunoreactivity after stimulation or inhibition of muscarinic receptors indicates anatomical specificity for cholinergic control of striatal efferent neurons and cortical neurons in the rat. Eur J Neurosci 5:1218-1225.

Bernard V, Somogyi P, Bolam JP (1997) Cellular, subcellular, and subsynaptic distribution of AMPA-type glutamate receptor subunits in the neostriatum of the rat. J Neurosci 17:819-833.

Bernard V, Laribi O, Levey AI, Bloch B (1998) Subcellular redistribution of $\mathrm{m} 2$ muscarinic acetylcholine receptors in striatal interneurons in vivo after acute cholinergic stimulation. J Neurosci 18:10207-10218.

Bloch B, Dumartin B, Bernard V (1999) In vivo regulation of intraneuronal trafficking of $\mathrm{G}$ protein-coupled receptors for neurotransmitters. Trends Pharmacol Sci 20:315-319.

Calne DB (1993) Treatment of Parkinson's disease. N Engl J Med 329:1021-1027.

Dournaud P, Boudin H, Schonbrunn A, Tannenbaum GS, Beaudet A (1998) Interrelationships between somatostatin sst2A receptors and somatostatin-containing axons in rat brain: evidence for regulation of cell surface receptors by endogenous somatostatin. J Neurosci 18:1056-1071.

Dumartin B, Caille I, Gonon F, Bloch B (1998) Internalization of D1 dopamine receptor in striatal neurons in vivo as evidence of activation by dopamine agonists. J Neurosci 18:1650-1661.

Dumartin B, Jaber M, Gonon F, Caren MG, Giros B, Bloch B (2000) Dopamine tone regulates D1 receptor trafficking and delivery in striatal neurons as evidenced using hyperdopaminergic mice. Proc Natl Acad Sci USA, in press.

Faure MP, Alonso A, Nouel D, Gaudriault G, Dennis M, Vincent JP, Beaudet A (1995) Somatodendritic internalization and perinuclear targeting of neurotensin in the mammalian brain. J Neurosci 15:4140-4147.

Fonseca MI, Button DC, Brown RD (1995) Agonist regulation of alpha $1 \mathrm{~B}$-adrenergic receptor subcellular distribution and function. J Biol Chem 270:8902-8909.

Giros B, Jaber M, Jones SR, Wightman RM, Caron MG (1996) Hyperlocomotion and indifference to cocaine and amphetamine in mice lacking the dopamine transporter. Nature 379:606-612.

Graybiel AM, Ragsdale Jr CW (1978) Histochemically distinct compartments in the striatum of human, monkeys, and cat demonstrated by acetylthiocholinesterase staining. Proc Natl Acad Sci USA 75:5723-5726.

Graybiel AM, Baughman RW, Eckenstein F (1986) Cholinergic neuropil of the striatum observes striosomal boundaries. Nature 323:625-627.

Hersch SM, Gutekunst C-A, Rees HD, Heilman CJ, Levey AI (1994) Distribution of $\mathrm{m} 1-\mathrm{m} 4$ muscarinic receptor proteins in the rat striatum: light and electron microscopic immunocytochemistry using subtypespecific antibodies. J Neurosci 14:3351-3363.

Hertel C, Coulter SJ, Perkins JP (1985) A comparison of catecholamineinduced internalization of $\beta$-adrenergic receptors and receptormediated endocytosis of epidermal growth factor in human astrocytoma cells. Inhibition by phenylarsine oxide. J Biol Chem 260:12547-12553.

Hirsch EC, Graybiel AM, Hersh LB, Duyckaerts C, Agid Y (1989) Striosomes and extrastriosomal matrix contain different amounts of immunoreactive choline acetyltransferase in the human striatum. Neurosci Lett 96:145-150.

Ince E, Ciliax BJ, Levey AI (1997) Differential expression of D1 and D2 dopamine and $\mathrm{m} 4$ muscarinic acetylcholine receptor proteins in identified striatonigral neurons. Synapse 27:357-366.

Kemel M L, Desban M, Glowinski J, Gauchy C (1992) Functional heterogeneity of the matrix compartment in the cat caudate nucleus as demonstrated by the cholinergic presynaptic regulation of dopamine release. Neuroscience 50:597-610.

Koenig JA, Edwardson JM (1996) Intracellular trafficking of the muscarinic acetylcholine receptor: importance of subtype and cell type. Mol Pharmacol 49:351-359.

Koenig JA, Edwardson JM (1997) Endocytosis and recycling of G protein-coupled receptors. Trends Pharmacol Sci 18:276-287.

Koenig JA, Edwardson JM, Humphrey PP (1997) Somatostatin receptors in Neuro2A neuroblastoma cells: ligand internalization. Br J Pharmacol 120:52-59.

Levey AI, Kitt CA, Simonds WF, Price DL, Brann MR (1991) Identification and localization of muscarinic acetylcholine receptor proteins in brain with subtype-specific antibodies. J Neurosci 11:3218-3226.

Lowenstein PR, Slesinger PA, Singer HS, Walker LC, Casanova MF, Raskin LS, Price DL, Coyle JT (1989) Compartment-specific changes in the density of choline and dopamine uptake sites and muscarinic and dopaminergic receptors during the development of the baboon striatum: a quantitative receptor autoradiographic study. J Comp Neurol 288:428-446.

Marvizon JC, Martinez V, Grady EF, Bunnett NW, Mayer EA (1997) Neurokinin 1 receptor internalization in spinal cord slices induced by dorsal root stimulation is mediated by NMDA receptors. $\mathrm{J}$ Neurosci 17:8129-8136.

McDonald TP, Dinnis DM, Morrison CF, Harmar AJ (1998) Desensitization of the human vasoactive intestinal peptide receptor (hVIP2/ PACAP R): evidence for agonist-induced receptor phosphorylation and internalization. Ann N Y Acad Sci 865:64-72.

Mundell SJ, Kelly E (1998) The effect of inhibitors of receptor internalization on the desensitization and resensitization of three Gs-coupled receptor responses. Br J Pharmacol 125:1594-600.

Muriel MP, Bernard V, Levey AI, Laribi O, Abrous DN, Agid Y, Bloch B, Hirsch EC (1999) L-DOPA induces a cytoplasmic localization of dopamine D1 receptors in striatal neurons in Parkinson's disease. Ann Neurol 46:103-111.

Nisenbaum LK, Kitai ST, Gerfen CR (1994) Dopaminergic and musca- 
rinic regulation of striatal enkephalin and substance $\mathrm{P}$ messenger RNAs following striatal dopamine denervation: effects of systemic and central administration of quinpirole and scopolamine. Neuroscience 63:435-449.

Parton RG, Simons K, Dotti CG (1992) Axonal and dendritic endocytic pathways in cultured neurons. J Cell Biol 119:123-137.

Pippig S, Andexinger S, Lohse MJ (1995) Sequestration and recycling of $\beta 2$-adrenergic receptors permit receptor resensitization. Mol Pharmacol 47:666-676.

Roettger BF, Rentsch RU, Pinon D, Holicky E, Hadac E, Larkin JM, Miller LJ (1995) Dual pathways of internalization of the cholecystokinin receptor. J Cell Biol 128:1029-1041.

Sternini C, Spann M, Anton B, Keith Jr DE, Bunnett NW, von Zastrow M, Evans C, Brecha NC (1996) Agonist-selective endocytosis of $\mu$ opioid receptor by neurons in vivo. Proc Natl Acad Sci USA 93:9241-9246.

Stoof JC, Drukarch B, de Boer P, Westerink BH, Groenewegen HJ (1992) Regulation of the activity of striatal cholinergic neurons by dopamine. Neuroscience 47:755-770.

van Deurs B, Holm PK, Kayser L, Sandvig K, Hansen SH (1993) Mul- tivesicular bodies in HEp-2 cells are maturing endosomes. Eur J Cell Biol 61:208-224.

Vogler O, Krummenerl P, Schmidt M, Jakobs KH, Van Koppen CJ (1999) $\rho$ A-sensitive trafficking of muscarinic acetylcholine receptors. J Pharmacol Exp Ther 288:36-42.

Wang JQ, McGinty JF (1996a) Muscarinic receptors regulate striatal neuropeptide gene expression in normal and amphetamine-treated rats. Neuroscience 75:43-56.

Wang JQ, McGinty JF (1996b) Scopolamine augments C-FOS and ZIF/ 268 messenger RNA expression induced by the full $\mathrm{D}(1)$ dopamine receptor agonist SKF-82958 in the intact rat striatum. Neuroscience 72:601-616.

Wang JQ, McGinty JF (1997) Intrastriatal injection of a muscarinic receptor agonist and antagonist regulates striatal neuropeptide mRNA expression in normal and amphetamine-treated rats. Brain Res 748:62-70.

Zimprich A, Simon T, Hollt V (1995) Cloning and expression of an isoform of the rat $\mu$ opioid receptor (rMOR1B) which differs in agonist induced desensitization from rMOR1. FEBS Lett 359:142-146. 